\title{
PROPOSTA DE MODELO CINÉTICO DA DEGRADAÇÃO DE LAMINADOS DE MADEIRAS EM AMBIENTES AQUÁTICO E TERRESTRE
}

\author{
APRILE, F. M., ${ }^{1}$ DELITTI, W. B. C. ${ }^{2}$ e BIANCHINI JR., I. ${ }^{3}$ \\ ${ }^{1} \mathrm{CPRH}$ - Cia. Pernambucana do Meio Ambiente \\ ${ }^{2}$ Depto. de Ecologia Geral, I. B., USP, SP \\ ${ }^{3}$ Departamento de Hidrobiologia, Universidade Federal de São Carlos, São Carlos, SP \\ Correspondência para: Fábio Marques Aprile, Departamento de Hidrobiologia, \\ Universidade Federal de São Carlos, São Carlos, SP \\ Recebido em 21/11/97 - Aceito em 11/8/98 - Distribuído em 10/09/99
}

(Com 4 figuras)

\begin{abstract}
Kinetics aspects of wood sheets decay on aquatic and terrestrial environments

A kinetic model for wood decomposition is proposed based on experimental data on the decomposition of wood from 12 species. The model takes into account the different decay coeficients for labile and recalcitrant compounds, in both terrestrial and aquatic ecosystems. It was verifed that: 1 . the oxidation process of recalcitrant fractions are the main pathway for mineralization, because the leaching and/ or mineralization of the labile compounds is low (less than 15\%); 2. the aquatic environment favour the decay processes and the increase of mineralization coefficients of recalcitrant fractions.
\end{abstract}

Key words: decay, kinetic model, wood.

\section{RESUMO}

Um modelo cinético da decomposição de madeiras é proposto a partir de experimentos de degradação de laminados de madeira de 12 espécies vegetais. São discutidos aspectos do decaimento desses recursos em termos cinéticos nos ambientes aquático e terrestre. De modo geral, verificou-se que: 1. o potencial de decaimento dos laminados, em função da lixiviação e/ou mineralização de compostos lábeis, é baixo (menores que 15\%), cabendo aos processos oxidativos das frações resistentes a principal rota de mineralização; 2 . o meio aquático tendeu a favorecer os processos de dissolução e verificaramse incrementos nos coeficientes de mineralização do material refratário.

Palavras-chave: degradação, modelo cinético, madeira.

\section{INTRODUÇÃO}

O crescimento da população mundial e a necessidade de inovações vêm forçando as indústrias a utilizar novas fontes de energia e fomentam o interesse na melhor utilização dos recursos naturais. Na lista de bens e recursos com interesse de reaproveitamento constam as madeiras submersas, presentes nas regiões alagadas por represamentos artificiais. Em particular, no Brasil, há uma grande incidência de reservatórios com essa ca- racterística, principalmente nas regiões norte e sudeste (Aprile, 1996). Em geral, na formação de um reservatório, a submersão da vegetação nativa restringe a exploração do potencial madeireiro da área e pode alterar significativamente as características da água (Bianchini Jr., no prelo). Tais fatores acabam dificultando a implementação de programas de usos múltiplos do reservatório. Para os reservatórios formados em áreas não-desmatadas verifica-se que, dependendo da densidade e tipo da fitomassa submersa, tais sistemas enfrentam 
déficit no balanço do oxigênio dissolvido que pode perdurar por muitos anos. Principalmente na fase de enchimento e durante os primeiros anos de operação, os processos de eutrofização podem, também, ser críticos. Nesse contexto, este trabalho tem por objetivo descrever e discutir aspectos cinéticos relativos à degradação de lâminas de madeiras de várias espécies vegetais, nos ambientes aquático e terrestre. Tem, ainda, por objetivo elaborar um modelo matemático capaz de simular e comparar os processos de decomposição nesses dois ambientes.

\section{MATERIAIS E MÉTODOS}

Os experimentos de decomposição, nos ambientes aquático e terrestre, foram realizados através do método tradicional de "litter bags" (Swift et al., 1979), no qual as bolsas de decomposição (naylon) apresentavam abertura de malha de $2 \mathrm{~mm}$. Nas bolsas que seriam mantidas no ambiente aquático foram colocados laminados (de 0,05 a 0,08 $\mathrm{cm}$ de espessura) de: cabriúva (Myrocarpus sp.), cedro (Cedrela sp.), cerejeira (Torresea cearensis), freijó (Cordia goeldiana), imbuia (Phoebe porosa), jacarandá da Bahia (Dalbergia nigra), jacarandá paulista (Machaerium villosum), louro preto (Ocotea sp.), mogno (Swietenia macrophylia), pinho (Araucaria augustifolia), pinus (Pinus sp.) e roxinho (Peltogyne discolor). Para o experimento desenvolvido em ambiente terrestre foram considerados os laminados de 5 espécies: cedro, cerejeira, freijó, imbuia e pinus. Para o experimento no ambiente aquático cada conjunto amostral foi constituído por 12 bolsas, sendo que cada uma continha 10 laminados de cada espécie. Para o experimento realizado no solo foram montados 12 conjuntos, sendo que cada um continha 1 bolsa para cada espécie. Cada bolsa portava também 10 laminados. Para a montagem do experimento as lâminas de madeira, com aproximadamente $50 \mathrm{~cm}^{2}$, foram previamente pesadas (Aprile et al., no prelo).

A cada dia de amostragem (dias: 30, 60, 90, $120,150,180,210,240,270,300,330$ e 360$) 1$ conjunto de bolsas de cada ambiente foi retirado (ambiente aquático: 12 bolsas e terrestre: 5 bolsas).

Após retiradas, as lâminas foram lavadas com água e limpas com pincel para a remoção do material aderido; em seguida, foram secadas em temperatura ambiente. A estimativa da perda de massa foi efetuada a partir do método gravimétrico. Os experimentos foram desenvolvidos na Reserva Florestal do CUASO, situada no campus da Universidade de São Paulo (Cidade Universitária Armando de Salles Oliveira, 6 ${ }^{\circ} 43^{\prime} \mathrm{W}$ e 23 $3^{\circ} 33^{\prime} \mathrm{S}$ ), onde encontra-se também a lagoa na qual foram mantidos os "litter bags". O número de lâminas depositado em cada bolsa e a temperatura de secagem (ambiente) foram estabelecidos após a realização de testes preliminares que visaram à adequação e otimização desses procedimentos (Aprile, 1996).

\section{RESULTADOS E DISCUSSÃO}

Através das Figs. 1 e 2 é possível observar que a maioria dos laminados mantidos na lagoa tenderam a apresentar uma perda de massa relativamente acentuada até o primeiro mês de experimento. A partir desse período, as perdas passaram a ocorrer de modo mais lento. A lixiviação e a oxidação dos compostos lábeis foram considerados como sendo os processos responsáveis por tais perdas iniciais.

Nesse contexto, é possível notar que os potenciais de dissolução/oxidação desses laminados de madeiras variaram entre, aproximadamente, zero (louro-preto) e $15 \%$ (imbuia). Na fase em que os processos oxidativos das estruturas refratárias predominaram e foram os responsáveis pelas perdas de massa (após o primeiro mês), verifica-se que as lâminas de cabriúva, cedro, cerejeira e freijó foram as que mais decaíram. Nesse período, as massas dos laminados de imbuia, praticamente, mantiveram-se inalteradas, indicando a maior refratabilidade desse recurso frente aos demais. Ainda em relação à perda de massa relativa aos processos de mineralização das estruturas resistentes, os laminados de jacarandá da Bahia, jacarandá paulista, louro-preto, mogno, pinho, pinus e roxinho apresentaram posição intermediária em termos de refratabilidade.

De modo geral, o potencial de lixiviação e as velocidades de dissolução e de mineralização dependem das características químicas do recurso, ou seja, o potencial de lixiviação refere-se ao conteúdo protoplasmático do recurso, a velocidade de lixiviação depende da composição do protoplasma e a velocidade de mineralização relaciona-se com o teor de frações lábeis (carboidratos, polifenóis etc.) e refratárias (lignina, celulose etc.) juntamente com a aptidão metabólica dos decompositores. Por 
envolver processos metabólicos ressalta-se que as alterações no tempo de variáveis ambientais, tais como: umidade, $\mathrm{pH}$, temperatura, teor de nutrientes, grau de oxigenação, tamanho de partículas e especificidade enzimática (tipos de organismos), devem
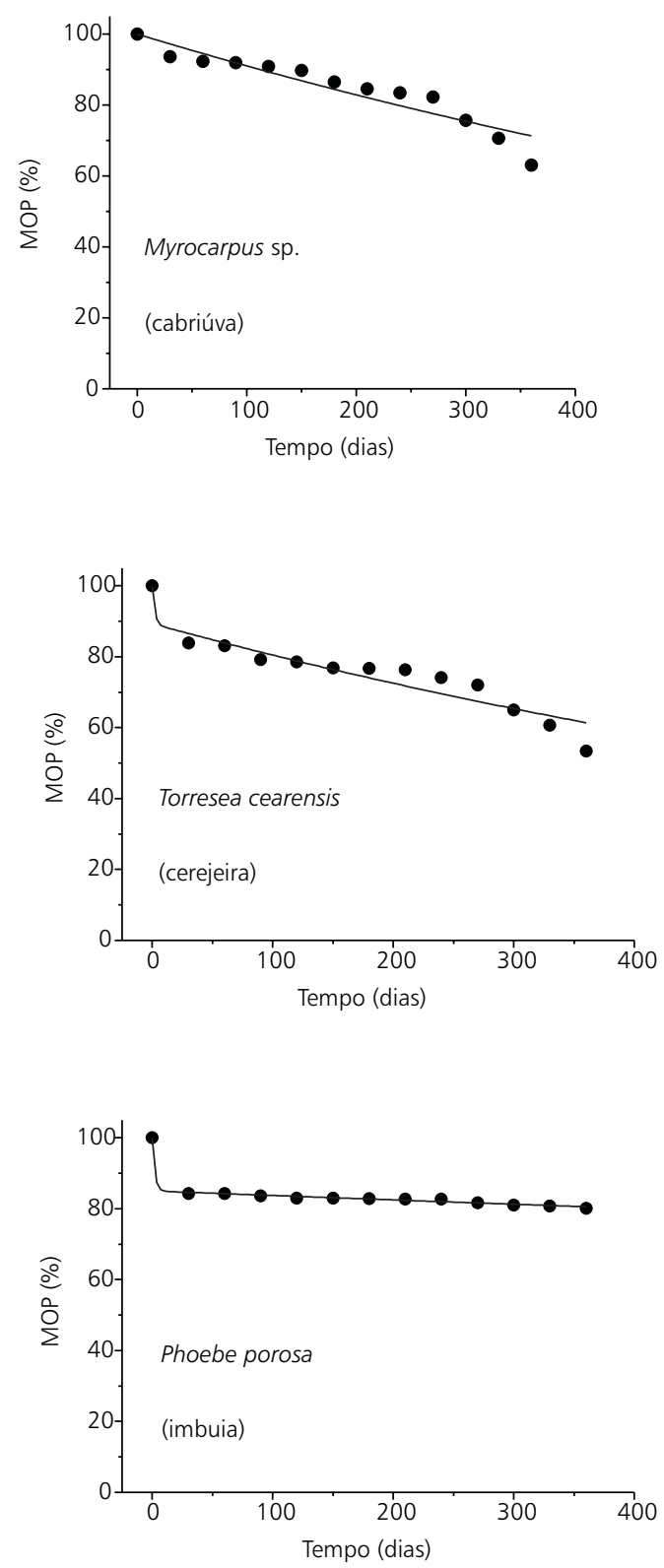

ser consideradas (Swift et al., 1979). Desse modo, os coeficientes de decaimento de longo prazo (após o primeiro mês) das lâminas de madeira das várias funções de força que atuaram durante os processos de mineralização desses recursos (Antonio, 1996).
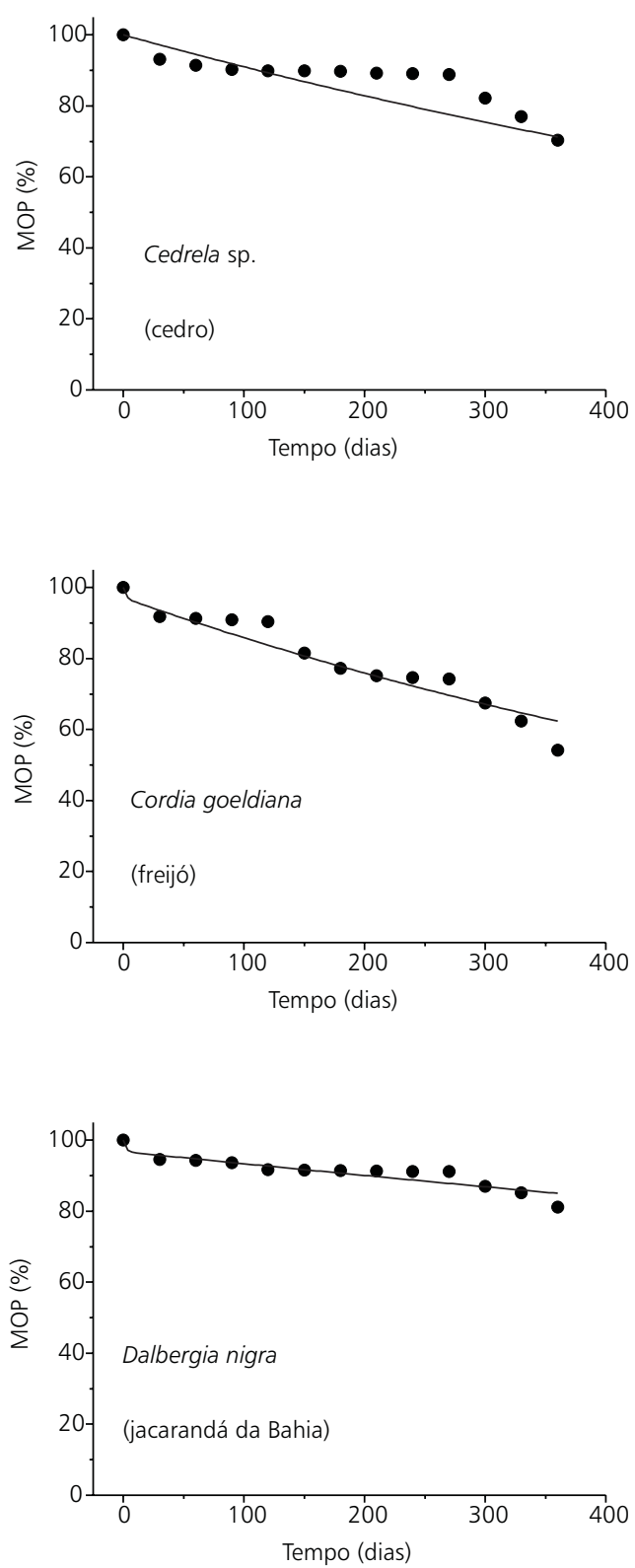

Fig. 1 - Degradação dos laminados de cabriúva, cedro, cerejeira, freijó, imbuia e jacarandá da Bahia em meio aquático (os pontos representam os valores médios das massas dos remanescentes). 

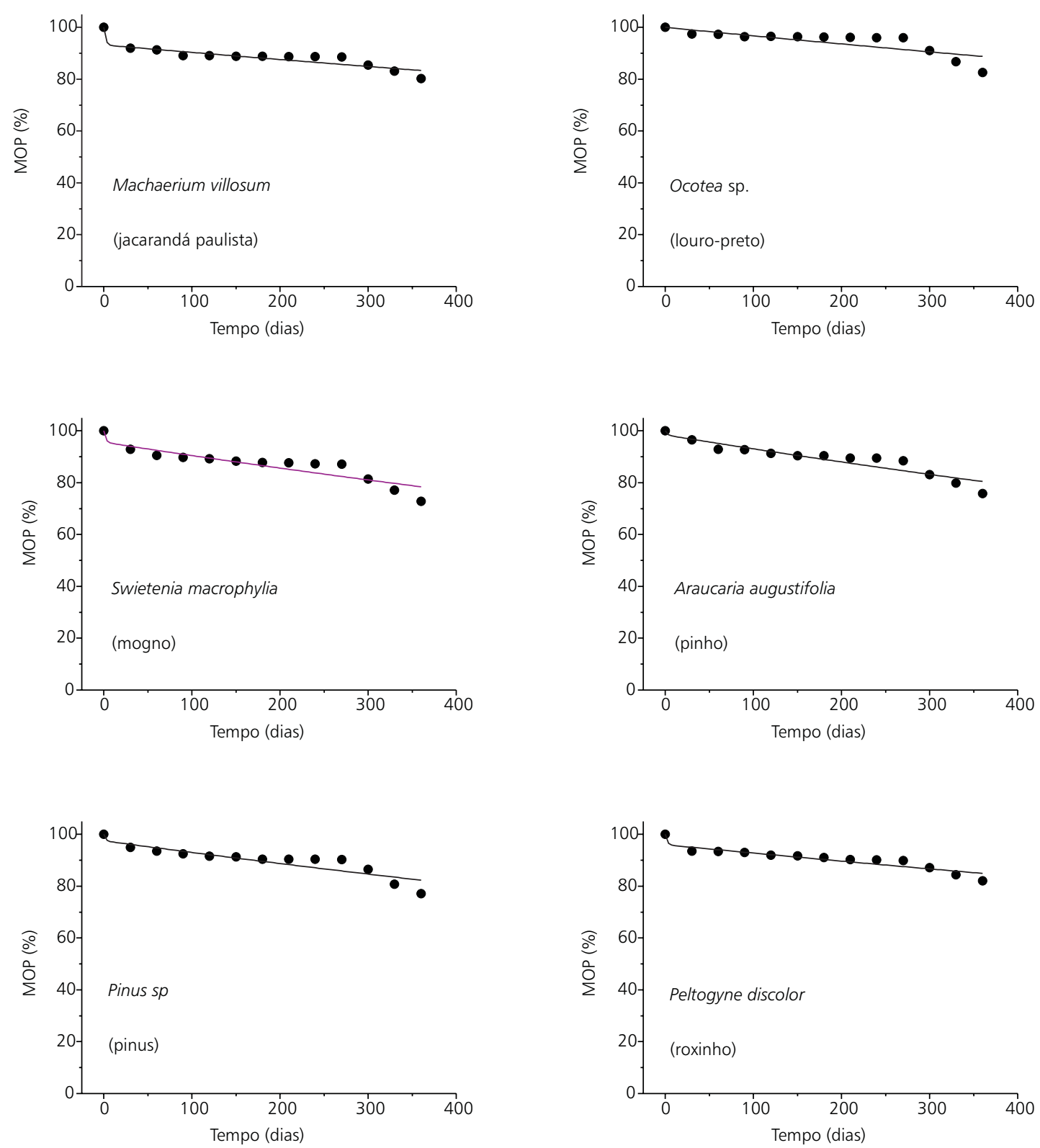

Fig. 2 - Degradação dos laminados de jacarandá paulista, louro preto, mogno, pinho, pinus e roxinho em meio aquático (os pontos representam os valores médios das massas dos remanescentes).

Os laminados depositados no solo, Fig. 3, apresentaram um decaimento mais uniforme, quando comparados com os obtidos da decomposição na lagoa (Fig. 1 e 2). Nesse caso, verifica-se que os processos de lixiviação foram fortemente inibidos, devido à natural restrição do conteúdo de água nesse ambiente. Comparando-se as perdas de massa ocorridas após o primeiro mês no solo com as verificadas no sistema aquático, nota-se que na água foram mais acentuadas. É possível que o ambiente aquático tenha favorecido a decomposição, graças à instalação de uma comunidade decompositora mais eficiente, ao acesso e transporte das exoenzimas e à ruptura das ligações químicas dos compostos refratários. Uma vez que é comum a prática da submersão de toras em rios e reservatórios como método de preservação de madeiras, os resultados obtidos sugerem que 
as degradações dos laminados em meio terrestre tenham sido atenuadas, provavelmente, devido ao impedimento da instalação de parte da macrofauna do solo, através da seleção imposta pelo tamanho de malha dos "litter bags". Neste caso, é possível supor para os dois experimentos que, devido
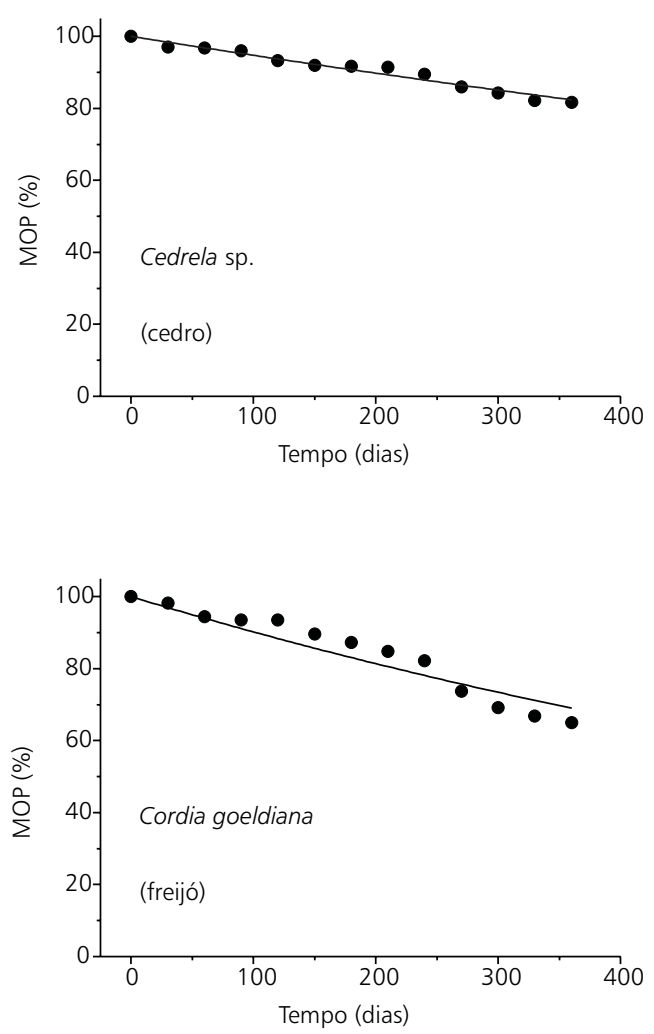

a esta limitação metodológica, as velocidades de mineralização tenham sido um pouco atenuadas. No solo, a exemplo do ocorrido na lagoa, notase que os laminados de cerejeira e freijó apresentaram as maiores perdas de massa em comparação com os demais recursos.
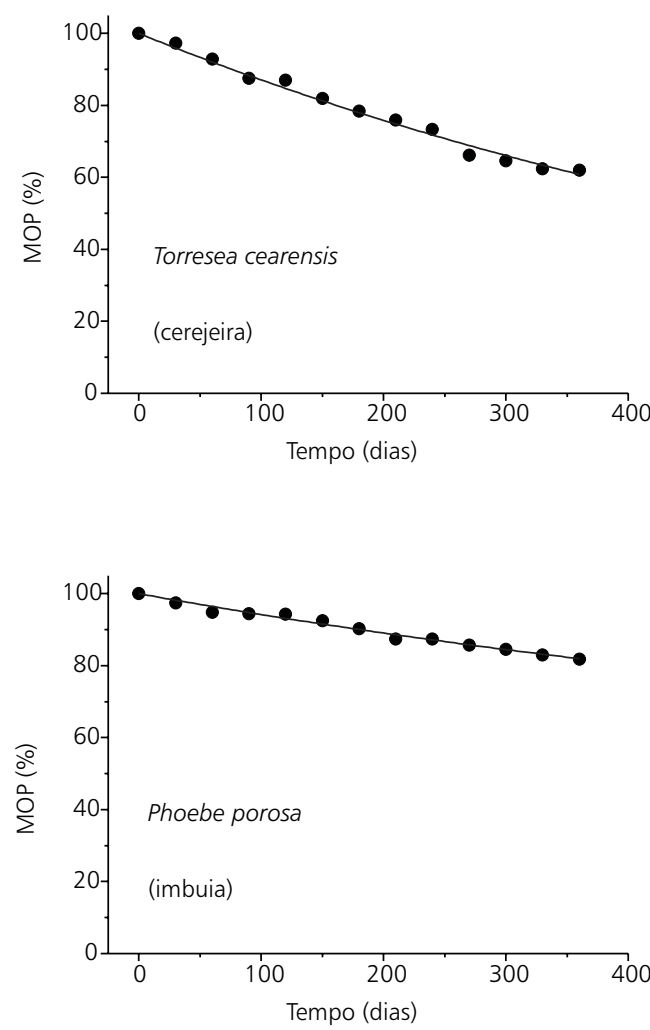

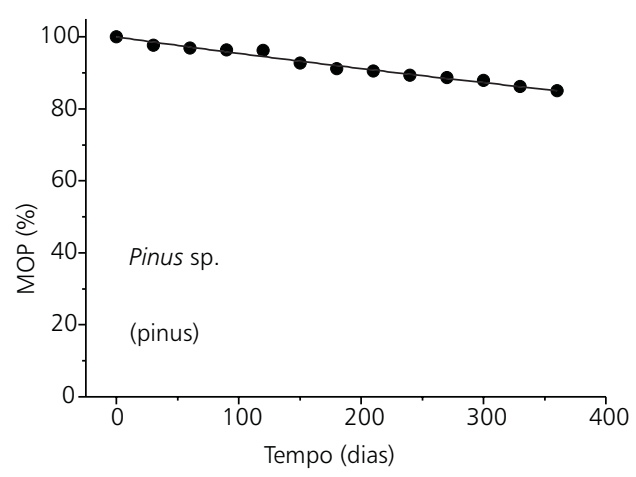

Fig. 3 - Degradação dos laminados de cedro, cerejeira, freijó, imbuia e pinus em meio terrestre (os pontos representam os valores médios das massas dos remanescentes). 
A análise dos resultados obtidos permitiu a elaboração de um modelo cinético que descrevesse, para os dois ambientes, os processos responsáveis pelas perdas de massa dos recursos devido à decomposição (Fig. 4). A exemplo do modelo sugerido por Bianchini Jr. \& Toledo (1996), admitiu-se que o decaimento da matéria orgânica particulada (MOP) tenha sido resultado da ação de três processos: a lixiviação das frações solúveis, a oxidação das frações lábeis e a oxidação das frações refratárias.

O modelo pressupôs que: 1. os processos cinéticos sejam de primeira ordem; 2. que a dissolução do lixiviado e a oxidação das frações lábeis ocorram em paralelo, ou seja, ao mesmo tempo que os processos de lixiviação ocorrem, o material lixiviado (frações protoplasmáticas) vai sendo oxidado pelos microrganismos (dentro ou fora da MOP); 3. as lâminas de madeira sejam recursos heterogêneos do ponto de vista químico (Mindermann, 1968), formados, neste caso, por duas classes de compostos: as frações lábeis e/ou solúveis e as frações refratárias. As frações lábeis e/ou solúveis corresponderiam, de modo geral, aos conteúdos protoplasmáticos (fração celular) e aos compostos estruturais com alta solubilidade (polifenóis, polissacarídeos, pigmentos, flavonóides, alcalóides etc.), sendo representadas no modelo através do parâmetro $\left(\mathrm{MOP}_{1}\right)$.

A perda de massa dos laminados devido a esta classe de compostos geraria, como produtos, a matéria orgânica dissolvida (MOD) e compostos inorgânicos $\left(\mathrm{IN}_{1}\right)$, sendo estes últimos decorrentes da ação metabólica dos operadores biológicos (fungos, bactérias etc.). Basicamente, entende-se por frações refratárias as constituídas pela matriz lignocelulósica e demais compostos estruturais refratários e/ou com baixa solubilidade. Em termos de modelo, essa classe de compostos foi representada pelo parâmetro $\mathrm{MOP}_{2}$ (conteúdo das frações refratárias do recurso); o catabolismo destas frações geraria como produto final o conjunto de compostos inorgânicos denominado $\mathrm{IN}_{2}$. Os coeficientes de decomposição (relativos às velocidades dos processos) foram representados por meio dos parâmetros $\mathrm{k}$. Em termos matemáticos, os processos descritos (e diagramados através da Fig. 4) foram representados pela Equação 1 .

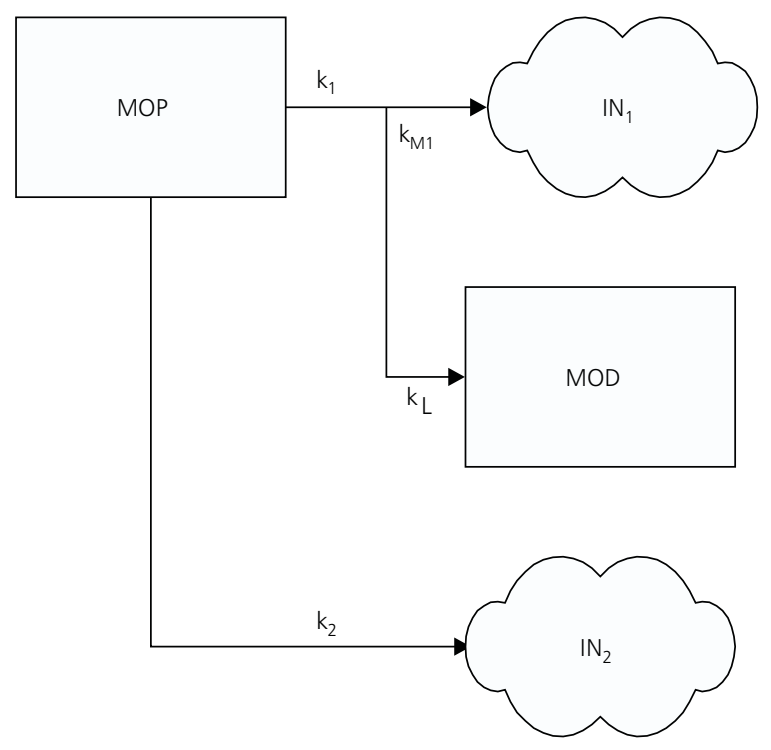

Fig. 4 - Modelo cinético proposto para a degradação dos laminados de madeira nos meios aquáticos e terrestres. $\mathrm{k}_{1}=$ coeficiente global de decaimento $\left(\mathrm{k}_{1}=\mathrm{k}_{\mathrm{L}}+\mathrm{K}_{\mathrm{M} 1}\right)$ das frações lábeis e/ou solúveis $\left(\mathrm{MOP}_{1}\right) ; \mathrm{k}_{\mathrm{L}}=$ coeficiente de lixiviação; $\mathrm{k}_{\mathrm{M} 1}=$ coeficiente de mineralização das frações lábeis; $\mathrm{k}_{2}=$ coeficiente de mineralização das frações refratárias $\left(\mathrm{MOP}_{2}\right) ; \mathrm{MOP}=\operatorname{composição}$ do recurso $\left(\mathrm{MOP}_{1}+\mathrm{MOP}_{2}\right)$. 
Equação 1:

$\frac{\mathrm{MOP}}{\mathrm{dt}}=-\mathrm{k}_{1} \mathrm{MOP}_{1}-\mathrm{k}_{2} \mathrm{MOP}_{2}$

em que:

MOP = variação da massa da matéria orgânica particulada, por unidade de tempo $\left(\mathrm{MOP}_{1}+\mathrm{MOP}_{2}\right)$;

$\mathrm{MOP}_{1}=$ variação da MOP relacionada com os conteúdos protoplasmáticos e outros compostos solúveis e/ou lábeis, por unidade de tempo;

$\mathrm{MOP}_{2}=$ variação da MOP relacionada com os compostos refratários, por unidade de tempo;

$\mathrm{k}_{1}=$ coeficiente global de decaimento (mineralização + lixiviação) das frações lábeis e/ou solúveis $\left(\mathrm{k}_{\mathrm{M}}+\mathrm{k}_{\mathrm{L}}\right)$, tempo ${ }^{-1}$;

$\mathrm{k}_{\mathrm{M}}=$ coeficiente de mineralização (oxidação) das frações lábeis, tempo ${ }^{-1}$;

$\mathrm{k}_{\mathrm{L}}=$ coeficiente de lixiviação das frações solúveis, tempo ${ }^{-1}$;

$\mathrm{k}_{2}=$ coeficiente de mineralização (oxidação) das frações resistentes, tempo ${ }^{-1}$.

A partir da integração analítica da Equação 1 , os resultados experimentais foram ajustados aos modelos cinéticos através de regressão não-linear (método dos mínimos quadrados implementado a partir de interações de Levenberg-Marquardt). Para cada tipo de laminado, após estimado o valor de MOP ${ }_{1}$ através do ajuste dos resultados da decomposição em meio aquático, o parâmetro foi fixado quando foi efetuado o ajuste dos resultados dos decaimentos no solo. Desse modo, admitiuse que as proporções entre as frações lábeis/solúveis $\left(\mathrm{MOP}_{1}\right)$ e refratárias $\left(\mathrm{MOP}_{2}\right)$ dos substratos fossem constantes nos dois experimentos. Nesse contexto, verifica-se que, em geral, a maioria dos recursos utilizados constituía-se principalmente de frações refratárias (de 85 a 100\%, Tabela 1). Em termos de decomposição de laminados de madeira, esses resultados minimizam os efeitos dos processos de lixiviação/oxidação de compostos lábeis e indicam a grande importância das rotas representadas por $\mathrm{k}_{2}$ frente às representadas por $\mathrm{k}_{1}$, tanto para o ambiente aquático quanto para $\mathrm{o}$ terrestre. Ou seja, os principais processos que resultaram, ou resultariam, na perda de massa desses substratos estiveram envolvidos com o catabolismo das frações resistentes.
$\mathrm{O}$ valor de $0,5 \mathrm{dia}^{-1}$, adotado várias vezes para $\mathrm{k}_{1}$ (coef. global de decaimento das frações lábeis/solúveis) nos ajustes das cinéticas de decomposição no ambiente aquático, deveu-se às incertezas dos resultados frente ao modelo proposto (Tabela 1). Tais incertezas decorreram da escassez de observações referentes aos primeiros 30 dias de experimento; período no qual ocorreram, relativamente, grandes perdas de massa. Para cabriúva e cedro, que apresentaram no ambiente aquático pouca perda de massa no primeiro mês e os recursos foram mantidos no solo, a falta de amostragens mais freqüentes nesse período não afetou o ajuste dos resultados, e os valores de $\mathrm{k}_{1}$ foram estimados satisfatoriamente.

Comparando-se os valores estimados para $\mathrm{k}_{2}$ (coef. de mineralização das frações refratárias) e as decomposições ocorridas na lagoa é possível classificar, em relação à refratabilidade, os laminados em 4 categorias. Na primeira, a dos recursos menos resistentes, incluíram-se as seguintes espécies: cabriúva, cedro, cerejeira e freijó. Nesta categoria foram classificadas as espécies que apresentaram uma meia-vida entre 1,5 e 2 anos. A segunda categoria, na qual a meia-vida da mineralização das frações resistentes situou-se entre 3,4 e 4 anos, incluíram-se o mogno, o pinho e o pinus.

A terceira categoria incluiu o jacarandá da Bahia, o jacarandá paulista, o louro-preto e o roxinho, que apresentaram, durante a decomposição, uma meia-vida entre 5,3 e 6,1 anos. A imbuia foi a única representante da quarta categoria por apresentar uma meia-vida da ordem de 12,7 anos.

No solo, com exceção dos laminados de imbuia e pinus, que apresentaram coeficientes globais de decaimento das frações lábeis e/ou solúveis $\left(\mathrm{k}_{1}\right)$ cerca de 6 e 9 vezes maiores que os respectivos coeficientes de mineralização das frações refratárias $\left(\mathrm{k}_{2}\right)$, a decomposição dos demais recursos teve uma proximidade numérica dos valores de $\mathrm{k}_{1}$ e $\mathrm{k}_{2}$, sugerindo assim que nesse ambiente praticamente não houve formação de lixiviados e que as perdas de massa de cedro, cerejeira e freijó decorreram somente da atuação dos processos oxidativos. Também nesse ambiente, a cerejeira e o freijó apresentaram uma meia-vida menor que 2 anos $(1,4 \mathrm{e}$ 1,8 anos, respectivamente). O cedro, que no ambiente aquático apresentou uma meia-vida de 2 anos, no solo apresentou o valor de 3,5 anos para este parâmetro. 
TABELA 1

Parâmetros relativos aos ajustes dos resultados do modelo cinético proposto.

\begin{tabular}{|c|c|c|c|c|c|}
\hline Recurso & MOP1 $_{1}(\%)$ & $k_{1}\left(\operatorname{dia}^{-1}\right)$ & $\mathrm{MOP}_{2}(\%)$ & $k_{2}\left(\operatorname{dia}^{-1)}\right.$ & $x^{2}$ \\
\hline \multicolumn{6}{|l|}{ Meio aquático } \\
\hline Cabriúva & 7,68 & 0,00091 & 92,32 & 0,00096 & 16,49 \\
\hline Cedro & 6,79 & 0,00068 & 93,21 & 0,00096 & 12,39 \\
\hline Cerejeira & 10,70 & 0,5 & 89,30 & 0,00104 & 12,77 \\
\hline Freijó & 2,90 & 0,5 & 97,10 & 0,00123 & 13,61 \\
\hline Imbuia & 15,00 & 0,5 & 85,00 & 0,00015 & 0,11 \\
\hline Jacarandá da Bahia & 3,20 & 0,5 & 96,80 & 0,00036 & 3,80 \\
\hline Jacarandá paulista & 6,81 & 0,5 & 93,19 & 0,00031 & 2,90 \\
\hline Louro-preto & 0,01 & 0,5 & 99,99 & 0,00033 & 8,25 \\
\hline Mogno & 4,40 & 0,5 & 95,60 & 0,00055 & 7,36 \\
\hline Pinho & 1,57 & 0,5 & 98,43 & 0,00056 & 6,45 \\
\hline Pinus & 2,50 & 0,5 & 97,50 & 0,00047 & 6,46 \\
\hline Roxinho & 4,01 & 0,5 & 95,99 & 0,00034 & 2,25 \\
\hline \multicolumn{6}{|l|}{ Meio terrestre } \\
\hline Cedro & 6,79 & 0,00052 & 93,21 & 0,00054 & 1,27 \\
\hline Cerejeira & 10,70 & 0,00139 & 89,30 & 0,00138 & 2,28 \\
\hline Freijó & 2,90 & 0,00101 & 97,10 & 0,00103 & 14,42 \\
\hline Imbuia & 15,00 & 0,00212 & 85,00 & 0,00035 & 0,63 \\
\hline Pinus & 2,50 & 0,00366 & 97,50 & 0,00040 & 0,51 \\
\hline
\end{tabular}

O pinus apresentou meias-vidas próximas nos dois ambientes (aquático: 4 anos e terrestre: 4,8 anos), no entanto, no meio aquático os processos oxidativos foram mais rápidos. Por apresentar uma meia-vida de 5,4 anos no ambiente terrestre, a imbuia mostrou-se muito mais resistente à decomposição no ambiente aquático. De modo geral, com base nos ajustes efetuados, verifica-se que os processos de lixiviação, de oxidação de compostos lábeis e de mineralização das estruturas refratárias foram favorecidos no decorrer da decomposição em ambiente aquático, com exceção dos laminados de imbuia e de cerejeira que se mostraram menos resistentes à decomposição no ambiente terrestre. Comparando-se os valores médios de $\mathrm{k}_{2}$ dos 5 laminados em decomposição nos dois ambientes verifica-se que na lagoa os processos de mineralização foram apenas $4 \%$ mais rápidos; ou seja, em termos médios, o processo de lixiviação foi o diferencial entre as perdas de massa nos dois ambientes.

As ordens de grandeza estimadas para os coeficientes $\mathrm{k}_{2}$ mostraram-se coerentes com as obtidas para recursos dessa natureza. Nesse con- texto, experimentos de decomposição com amostras de folhas, cascas, galhos (compostas por várias espécies vegetais) e serapilheira, desenvolvidos em laboratório, em meio aquático e condições anereróbias (Bianchini Jr. et al., 1997), apresentaram os seguintes coeficientes de mineralização das frações resistentes dos recursos $\left(\mathrm{dia}^{-1}\right): 0,052$ (folhas), 0,0019 (galhos), 0,0032 (cascas) e 0,0040 (serapiheira). Para condições aeróbias, nesse mesmo experimento, estimaram-se os seguintes valores para os coeficientes análogos ao $\mathrm{k}_{2}\left(\mathrm{dia}^{-1}\right)$ : 0,014 (folhas), 0,007 (galhos), 0,007 (cascas) e 0,008 (serapiheira). Do ponto de vista da qualidade da água dos reservatórios, os resultados obtidos permitem supor que os fustes não se constituem, necessariamente, em grandes fontes de matéria orgânica dissolvida, caso sejam submersos durante a formação dos reservatórios. Por constituiremse basicamente de compostos refratários, as degradações desses recursos são, em geral, muito lentas; por esse motivo, não devem contribuir significativamente para as demandas de oxigênio dissolvido dos reservatórios. 


\section{CONCLUSÕES}

Com base nos ajustes dos resultados ao modelo de decomposição desenvolvido concluiu-se que: 1. devido a proporção entre os compostos solúveis/lábeis e os refratários dos recursos, os processos de lixiviação e/ou oxidação dos compostos lábeis contribuiram de forma secundária para a perda de massa dos detritos, sendo os processos de degradação dos laminados de madeira, principalmente, efetuados por meio das rotas catabólicas dos decompositores; e 2. de modo geral, os processos de lixiviação, de oxidação de compostos lábeis e de mineralização das estruturas refratárias tenderam a ser favorecidos na decomposição em ambiente aquático.

Agradecimentos - À CAPES pela bolsa de estudo concedida; à prof. Dra. V. A. Alfonso e ao pesq. H. L. Oliveira Filho (Depto. de Botânica - IBUSP) pela identificação do material; à bióloga L.A. Silva.

\section{REFERÊNCIAS BIBLIOGRÁFICAS}

ANTONIO, R. M., 1996, Estimativa da capacidade heterotrófica do lago infernão (estação ecológica de Jataí, SP). Dissertação de Mestrado, PPGERN, UFSCar, São Carlos.

APRILE, F. M., 1996, Cinética de decomposição de madeiras em ambiente aquático e terrestre. Dissertação de Mestrado, Departamento de Ecologia Geral, Instituto de Biociências (USP), São Paulo.

APRILE, F. M., DELITTI, W. B. C. \& BIANCHINI JR., I., Aspectos cinéticos da degradação de laminados de madeira em ambientes aquático e terrestre (no prelo).
BIANCHINI JR., I. \& TOLEDO, A. P. P., 1996, Estudo da mineralização de Eleocharis mutata. Anais Sem. Reg. Ecol., 7. São Carlos, UFSCar, pp. 57-72.

BIANCHINI JR., I., ANTONIO, R. M. \& BITAR, A. L., 1997, Plano de controle ambiental tijuco alto: ensaios da degradação da vegetação a ser submersa. Rel. Técnico, Contrato FAI-UFSCar/CBA, 30.ago.95, São Carlos, SP.

BIANCHINI JR., I. The degradation process of organic matter in reservoirs. Anais do international workshop on greenhouse gas emissions from hydroelectric reservoirs (no prelo).

MINDERMANN, G., 1968, Addition, decomposition and accumulation of organic matter in forests. J. Ecol., 56: $355-562$

SWIFT, M. J., HEAL, D. W. \& ANDERSON, J. M., 1979, Studies in ecology-decomposition in terrestrial and aquatic ecosystems. Oxford, Blackwell. 